\title{
Alicia Steimberg \\ Recuerdos y reflexiones sobre la constitución de mi condición de escritora judía latinoamericana
}

\section{Resumen}

Las religiones, creencias-identidad en Buenos Aires. Católicos, judíos, protestantes. El catolicismo, simple y mayoritario. La comunidad judía, minoritaria y con un discurso religioso de definición más compleja. Los protestantes. Mi propia inserción en la sociedad argentina. Las clases sociales. La franja de los intelectuales. La heterogeneidad y la mezcla en todos los grupos religiosos o de identidad. La escolaridad como primera ocasión del descubrimiento de la propia identidad. Se puede dejar de ser católico, pero no se puede dejar de ser judío. Se puede ser judío sin ser judío y tampoco católico. Se puede no ser creyente sin ser ateo. ¿Cómo se sostienen los planetas en el espacio sin caerse nunca? ¿Quién "hizo" los planetas? No tomo la primera comunión porque "nosotros no tenemos esa costumbre".

Un barrio de Buenos Aires como escenario de la infancia. El barrio judío se dispersa. Los nuevos inmigrantes que no figuraban en la época del sainete. 1939: mi entrada en la escuela primaria y el comienzo de la Segunda Guerra Mundial. 1945: termina la guerra y entro en la secundaria. La guerra pasa lejos de Buenos Aires. En la escuela descubro que mi apellido no es español ni italiano: es alemán y judío. O judío alemán. Y con un error de ortografía. Pero mis abuelos no son alemanes, son rusos. Es fácil ser hijo o nieto de españoles o de italianos. Es difícil ser ruso y tener un apellido alemán judío. O judío alemán. No voy a misa ni tomo la primera comunión porque los judíos "no tenemos esa costumbre". Otros tienen la costumbre de creer en Dios.

\section{Texto}

Cándidamente, como se piensa lo que uno va a escribir antes de empezar a escribirlo, hablaré primero de los judíos porteños en la actuali- 
dad, a quienes conozco, porque, como diría Macedonio Fernández, el universo y yo nacimos en Buenos Aires, el 18 de julio de 1933. Nací judía, aunque eso lo supe años después; no sé cómo ni quién me lo dijo. Lo cierto es que a mis ocho años lo sabía, sin que yo recuerde si alguien me lo dijo con esas palabras. Ya había hablado de esto con mi padre, en una vuelta a la manzana que solíamos dar, él y yo, después del almuerzo, antes de que él volviera a su trabajo. La palabra "judío" o "judía" jamás ha sido tan indiferente, tan plana para mí, como la palabra "católico" o la palabra "protestante". Entré en el año 1939 a la escuela primaria, gratuita, laica y obligatoria, según la Ley 1420 de Enseñanza de la Constitución Argentina. No hubo gueto para mí en mi infancia ni en todo lo que va de mi vida, y sólo me enteré a mis doce años de lo que había pasado en Alemania y otros países europeos a los judíos y todos aquellos que se oponían al régimen. Papá murió en 1941, en plena guerra, cuando él tenía 42 años y yo ocho. Me enteré de lo sucedido en Europa cuando la guerra ya había terminado y por una compañera de colegio que tenía en su poder publicaciones con fotos de los campos de concentración, las ristras de cadáveres esqueléticos colgados de los alambres de púa y las pilas de zapatos, ropa, anteojos, prótesis dentales que les habían arrancado a los prisioneros antes de llevarlos a las cámaras de gas. Mis compañeras de la escuela eran en su gran mayoría católicas. Siempre había dos o tres que eran judías, como yo, pero no creo que tuvieran ansiedad por ese motivo. Las católicas solían tener apellidos españoles o italianos, como Fernández o Bellagamba, por la masa inmigratoria que había ingresado en el país en las dos o tres décadas anteriores, y muchas descendían de españoles por una rama y de italianos por la otra. Pero si una se llamaba Alicia Steimberg, o Celia Breslier, o Rebeca Mankowsky, o Jovita Kobrinsky, o Delia Kohan, cada tanto debía responder a quienes le preguntaban: “¿Y qué es ese apellido?”. Tampoco aparece entre mis recuerdos la primera vez que me lo preguntaron. Yo, de mala fe, puesto que conocía la respuesta, le pregunté a mi madre: “¿Qué debo decir cuando me preguntan qué es el apellido Steimberg?". "Decí que es alemán judío", me respondió. Procedí a contestar de esa manera y me tranquilicé bastante, porque una vez obtenida esa respuesta los curiosos, o mejor dicho las curiosas, ya que solían ser las chicas las que averiguaban, no seguían preguntando. De allí en adelante, sobre todo cuando me acerqué a la edad en que las niñas comienzan a inte- 
resarse en los muchachos y los muchachos en las niñas, me llegaron algunas indicaciones de mis mayores sobre la forma de elegir novio. "Mejor que sea un muchacho judío", me decían mi abuela y mis tías. Mamá, como de costumbre, no hablaba, o no estaba presente. Era una mujer que "trabajaba", esto quería decir que no se dedicaba únicamente a la casa y los niños, sino que tenía una profesión y la ejercía. Aunque no hubiera sido profesional, sino simplemente empleada de oficina, o hubiera tenido un oficio como el de peluquera, o el de vendedora de tienda, o el de modista o el de portera de un edificio, era una mujer que trabajaba.

"Los muchachos judíos son mejores que los cristianos", aseguraban la abuela y las tías (no decían "católicos" sino "cristianos", palabra esta más abarcadora porque incluía a los protestantes, una comunidad menor que la de los judíos. No hay tradición protestante en estos países latinoamericanos. Hay hijos de protestantes, hay nietos de protestantes, aunque esto es menos frecuente, pero en Latinoamérica más bien la gente ingresa en las religiones protestantes por ideología o por convicción).

Les contaré un sueño reciente que anoté para que no se convirtiera en la bruma de los sueños habidos, desflecados y desaparecidos de toda la humanidad, y aun de los monos que nos precedieron y de los perros que nos acompañan. "Sueña el can", dice Francisco de Quevedo en su libro Los sueños, publicado por primera vez en el año 1604, "con los hechos que hubieron de sucederle ese día".

Siglos después, el austríaco Sigmund Freud, dijo en lengua alemana: "Uno sueña con uno".

En el sueño yo era una niñita perdida en el mundo, de la mano de adultos que la cuidaban y que por su severidad parecían ser de la policía, aunque tal vez no lo eran, pero mamá murió hace treinta años y papá hace más años todavía, y con la Policía me he encontrado recientemente cuando tuve que renovar mi pasaporte y ellos no lo hicieron a tiempo, y esa es la causa de mi ausencia física en este Simposio.

Pero vamos a los temas que anuncié en mi resumen, para que no me pierda, según mi costumbre, en vanas especulaciones y asociaciones libres que son buenas y hasta recomendables para la literatura, una forma de narración que está lejos de servir siempre a la verdad, destinada a entretener al lector, aunque, cuando ha pasado algún tiempo y 
se convierte en historia, se use también para aportar datos a otras disciplinas más serias.

En la ciudad de Buenos Aires, lo mismo que en el resto del país y en cualquier país latinoamericano, los judíos son minoría. Pero hay judíos en todos los países. No daré cifras, en todo caso diré, sin temor a equivocarme, que las comunidades judías, aunque no se comporten como verdaderas comunidades, son siempre una minoría del total de la población. En el caso de Argentina la posible diferencia entre judíos y no judíos es: población total, alrededor de 40 millones de personas, comunidad judía: 500.000 almas o menos, porque esa era la cifra en la primera mitad del siglo veinte, y sabemos que disminuyó, debido a que junto con otros argentinos no judíos, muchos argentinos judíos emigraron a otros países, unos en pos de un nivel socioeconómico más satisfactorio y otros, durante la dictadura militar, por ser parte de los perseguidos políticos.

Volvamos a mí. Teníamos, mi familia y yo, una niñita, que era mía y de las personas que me acompañan en este avanzado período de mi vida. Ella caminaba por una calle de Buenos Aires, pero aún no había aprendido a hablar, aunque cada tanto dejaba escapar sonidos sin significado. Parecía tranquila y un poco tonta como cualquiera que no sabe hablar en el idioma de quienes la rodean. Así fueron mis primeros tiempos, o tiempitos, en este mundo. Salí del vientre de mi madre por la vía tradicional y, según me contó ella, con gran sufrimiento de su parte, en la maternidad del Hospital Rivadavia, en Buenos Aires, en 1933. Cuando por fin me habló de eso, mamá sólo se refirió en primer lugar al sufrimiento que yo le causé al salir al mundo. Cuando tuve edad para entender de qué me estaba hablando, le oí decir con frecuencia: "Pasé una noche sin dormir para que vos nacieras". "Pero”, pensaba yo, “¿no valía yo una noche sin dormir?” Y mamá agregaba, soñadora: "En cuanto naciste me dieron un gran vaso de leche tibia". Entre tanto la partera esperaría la salida de la placenta y las enfermeras me estarían bañando y adecentando mientras mi madre, después de una noche entera de dolor, mi madre, la doctora Luisa Imas de Steimberg, odontóloga, que me había hecho el gran favor de parirme aquella madrugada (mala noche y parir hembra), para que pudiera respirar el aire de este mundo, bebía el mencionado vaso de leche. 
Al cesar los alaridos de mi madre y ser reemplazados por mis berridos todo volvió a su cauce, y poco después, bañada, entalcada, vestida con mi ajuar de bebé, batita de algodón, batita tejida, babero bordado, ombliguero, pañal fino, pañal grueso, faja arrollada alrededor de mi pancita, fui puesta en sus brazos, y lo único que le quedó a ella, a mi madre, como recuerdo de la gesta, no fue mi pequeña anatomía, los diez deditos de mis manos y los diez deditos de mis pies, mis párpados hinchados, mi carita crispada de angustia por haber tenido que pasar por un túnel demasiado angosto para mi cabeza. Lo que quedó en su memoria fue aquel gran vaso de leche tibia con que calmó su hambre y su sed y selló la desaparición del dolor y su precioso bienestar recuperado como por encanto.

"Nací, hermanos, en esta dulce tierra argentina, pero el primer recuerdo nítido de mi infancia..."

Los versos son de Baldomero Fernández Moreno, y menos de veinte años después de mi sanguinolenta aparición en este mundo los leería como propios, como si me representaran fielmente y de la manera más absoluta. Había nacido una criatura de sexo femenino, sana, de un poco menos de tres kilos de peso, en Buenos Aires, Argentina, Sudamérica. Yo.

Pero falta el detalle que justifica toda esta historia. El detalle es que en esa carita con el ceño fruncido y el pulgar férreamente hundido en la boca para chuparlo a mi placer -eso no podían impedírmelohabía una señal invisible que sólo años después yo llegaría a reconocer, y que cualquiera aprendería a reconocer con solo ver mi apellido: la Estrella de David.

\section{Domingo 15 de noviembre}

Anoche dormí mal, soñé con el viaje. Se podría decir que la noche, desde que me acosté, fue un solo y terrible ataque de pánico. Sin embargo sólo ahora, a las 8 y 23 de esta mañana nublada, gris y algo ventosa, se va levantando la niebla en mi cabeza. El sueño de anoche no fue más que otro capítulo de una serie de sueños que tengo desde hace muchísimos años, más precisamente desde que empecé a viajar a Estados Unidos a hablar de los Jewish Latin American Writers. En el sueño voy a tomar un avión en el andén de una estación de subterráneo. El avión no llega. Y no llega. Pero además me doy cuenta de que 
no tengo el pasaje, no tengo equipaje, y no tengo dinero para vivir allá en Estados Unidos. En 1983 gané una beca Fulbright para escritores. Mi único libro publicado era Músicos y relojeros. Después escribí y publiqué diez libros más, con buen éxito. El tema judío, si es que mi judaísmo es un tema literario, sólo aparece manifiestamente en dos de mis libros: Músicos y relojeros y Cuando digo Magdalena.

Debo mencionar la muerte de un joven padre judío argentino que había nacido en una de las Colonias Judías Entrerrianas, sucedida en Buenos Aires el 24 de agosto de 1941.

Ya he ido sumando a muchos de mis seres queridos que se fueron de este mundo y están en otro. Cuando murió papá yo, a pesar de mis escasos ocho años, sabía que eso podía suceder. Uno de mis tíos me enteró de su muerte, estando yo apoyada en la vieja pared del patio. Como mi padre vivió en casa su última enfermedad que duró ocho días y se lo llevó, atendido por una junta de médicos y una de sus hermanas que era enfermera, parecía que todo quedaba entre nosotros. Con increíble sabiduría, mi abuela, la única que se mantuvo sobria y no entró en paroxismos de llanto como los demás, atendió a mis escasas necesidades. No recuerdo en esos días haberme sentado a la mesa a comer ni a tomar nada, pero no importan mis recuerdos. De alguna manera sobreviví. Mi madre permaneció acostada, se negó a ir a la habitación donde velaban a su esposo - yo sí fui, y vi una impresionante cantidad de flores, un lecho de flores alrededor de la mesa, y en el centro de la mesa alcancé a ver una esquina del ataúd lustroso donde estaba mi padre. Cerrado. Y en la tapa, aunque no sé si entonces la percibí, la Estrella de David. Después oí a mi madre quejarse histéricamente de que a mi padre lo velaran y fueran a enterrarlo según estrictas normas rituales judías. Eso lo decidieron mis tíos paternos.

\section{Conclusión}

Como siempre que preparo un texto para leerlo en público, no estoy segura de que lo narrado coincida con las expectativas de ustedes, los que me escuchan. Pero si deseaban saber cómo es la vida de un escritor judío latinoamericano, creo que he dado una idea bastante clara. Nadie me pidió cuentas, nadie me preguntó por qué era judía ni por qué habría preferido ser católica o protestante. Pero jamás, ni un solo día de mi vida, he dejado de pensar que soy judía. 